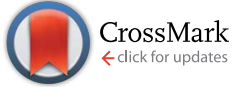

Cite this: RSC Adv., 2017, 7, 12006

Received 30th December 2016 Accepted 13th February 2017

DOI: $10.1039 / c 6 r a 28864 b$

rsc.li/rsc-advances

\section{A Pd nanocatalyst supported on multifaceted mesoporous silica with enhanced activity and stability for glycerol electrooxidation $\dagger$}

Thiago S. D. Almeida, ${ }^{a}$ Katia-Emiko Guima, ${ }^{a}$ Roberto M. Silveira, ${ }^{\text {bc }}$ Gabriel C. da Silva, ${ }^{d}$ Marco A. U. Martines ${ }^{b}$ and Cauê A. Martins*a

Glycerol is massively produced as a byproduct of biodiesel manufacturing, which decreases its price and increases its inadequate disposal. The use of glycerol to feed anodes of alkaline fuel cells and electrolysers has emerged as potential alternatives for its use. However, the activity and stability of commercial $\mathrm{Pd} / \mathrm{C}$ nanoparticles currently proposed do not reach the required performance. Here, we propose a new $\mathrm{Pd}$ catalyst deposited in mesoporous silica $\left(\mathrm{SiO}_{2}\right)$ with enhanced activity and stability for glycerol electrooxidation in alkaline media. We synthesized well-ordered mesoporous silica with pores in the form of a fountain pen and $I m \overline{3} m$ symmetry, in a cage-like arrangement. Such a structure was proved by experiments of microscopy, $\mathrm{X}$-ray diffraction, $\mathrm{N}_{2}$ isotherms and small-angle $\mathrm{X}$-ray scattering measured in synchrotron light. Next, we produced patterned $\mathrm{Pd} / \mathrm{SiO}_{2}$ in a one-step synthesis and ordered $\mathrm{Pd}$ after template removal. The $\mathrm{Pd}$ catalysts were characterized by microscopy, dispersive $\mathrm{X}$-ray spectrometry and X-ray diffraction. $\mathrm{Pd} / \mathrm{SiO}_{2}$ and $\mathrm{Pd}$ showed improved current density and stability compared to $\mathrm{Pd} / \mathrm{C}$. The current density of $\mathrm{Pd} / \mathrm{SiO}_{2}$ reached twice the values found for $\mathrm{Pd} / \mathrm{C}$. The enhancement is understood as a multiple role of the mesoporous silica support, which works as a seed mediator to order the $\mathrm{Pd}$ nanoparticles and mainly as a trap that confines the reactant inside the mesoporous structure, increasing the frequency of collision with active Pd sites. Furthermore, we showed that no carbonyl or intact glycerol was found on $\mathrm{Pd} / \mathrm{SiO}_{2}$ after exhaustive cycles of use, except for adsorbed $\mathrm{CO}$ that was quickly removed from the surface, which is a probable reason for an improved pathway of glycerol electrooxidation via CO.

\section{Introduction}

Biodiesel fabrication by the transesterification of vegetable oil or fat produces glycerol as $10 \mathrm{wt} \%$. Thus, a high amount of glycerol has been generated as a byproduct, leading to a decay in price and increasing the risk of its inadequate disposal. In this context, the glycerol electrooxidation reaction (GEOR) has been investigated as a potential fuel for direct alcohol fuel cells (DAFC) since the threehydrated carbon can be converted into $\mathrm{CO}_{2} \cdot{ }^{1}$ On the other hand, its total electrooxidation is circumvented due to partial electrooxidation in parallel reactions to form carbonyl compound $s^{2}$ on carbon-supported Pt nanoparticle (NP) catalysts. ${ }^{3}$ This apparent

${ }^{a}$ Faculty of Exact Sciences and Technology, Universidade Federal da Grande Dourados, 79804-970 Dourados, MS, Brazil.E-mail: cauemartins@ufgd.edu.br

${ }^{b}$ Institute of Chemistry, Universidade Federal de Mato Grosso do Sul, C.P. 549, 79070900 Campo Grande, MS, Brazil

'Instituto Federal de Educação, Ciência e Tecnologia de Mato Grosso do Sul-Campus Ponta Porã, C.P. 79900-000 Ponta Porã, MS, Brazil

${ }^{d}$ Instituto de Química de São Carlos, Universidade de São Paulo, IQSC-USP, C.P. 780, São Carlos, SP, Brazil

$\uparrow$ Electronic supplementary information (ESI) available. See DOI: $10.1039 / \mathrm{c} 6 \mathrm{ra} 28864 \mathrm{~b}$ disadvantage is in fact an opportunity to produce highly valuable compounds from glycerol. ${ }^{4-7}$

Pd-based nanocatalysts have been recently used to improve the catalytic properties of GEOR in alkaline media. ${ }^{8-13}$ Some works show the influence of multimetallic Pd-based NPs immobilized on a carbon support on GEOR. ${ }^{11,13}$ Although most of the thermodynamics and kinetics of the surface reaction are a function of the physical-chemical characteristics of the metallic catalysts, the NP supports play a central role in their stability. It is well known that the commercial amorphous carbon supports used in fuel cells do not present adequate stability for the long term. ${ }^{\mathbf{1 4}}$ Thus, new supports for Pd NPs capable of maintaining the activity of the catalysts for long periods of operation are imperative to make glycerol fuel cells (and electrolysers) feasible. Su et al. used $\mathrm{Pd} / \mathrm{TiO}_{2}$ nanofibres to improve GEOR besides other small-chain alcohol electrooxidation reactions. ${ }^{12}$ Zalineeva et al. used a self-supported porous PdBi catalyst for GEOR in an alkaline medium. ${ }^{9}$ The authors reported an outstanding improvement in current density and in electrochemical stability in terms of keeping the current density during long periods of potentiostatic experiments. ${ }^{9}$ 
Oxides such as $\mathrm{SiO}_{2}$ have emerged as powerful supports for metallic NPs since they combine qualities such as high durability ${ }^{\mathbf{1 5}}$ and activity. ${ }^{\mathbf{1 6 - 1 8}} \mathrm{SiO}_{2}$ structures can be spatially controlled to generate highly oriented surfaces containing pores, which might work as cages to confine the reactants, ${ }^{19}$ improving the catalysis performance by increasing the collision frequency. Shim et al. synthesized bimetallic PtPd NPs well dispersed on the wall of mesoporous carbon/silica composites with enhanced activity for formic acid oxidation in terms of mass activity and onset potential. ${ }^{18}$ Melvin et al. synthesized hollow silica sphere supports for Pt NPs with high catalytic activity for methanol electrooxidation. ${ }^{\mathbf{1 6}}$ Azizi et al., also working with methanol electrooxidation, found that $\mathrm{Ni}$ supported on mesoporous silica increases the output current density of the reaction in alkaline media, working as a Pt-free catalyst. ${ }^{17}$

The physical-chemical properties and spatially ordered structure of $\mathrm{SiO}_{2}$ increase its use in several kinds of energy technology ${ }^{20}$ and even in heterogeneous non-electrochemical catalysis. $^{21,22}$ In this context, we synthesized ordered Pd nanostructures over highly ordered mesoporous silica and evaluated their activity and stability for GEOR in alkaline media.

\section{Experimental}

\section{Synthesis of mesoporous $\operatorname{lm} \overline{3} m$ silica}

The synthesis of mesoporous silica was carried out based on a previous report ${ }^{23}$ with modifications, which allowed the production of multifaceted $\operatorname{lm} \overline{3} m$ silica. Firstly, we prepared a micellar solution and added the silica precursor for hydrolysis and the self-assembly procedure. For that, $1.5 \mathrm{~g}$ of Pluronic F127 surfactant was dispersed in $100 \mathrm{~mL}$ of water at $\mathrm{pH} 1.5$ (adjusted with $2.0 \mathrm{~mol} \mathrm{~L}{ }^{-1} \mathrm{HCl}$ ) and stirred at room temperature to reach a homogeneous solution. Afterwards, $3.53 \mathrm{~g}$ of tetraethyl orthosilicate (TEOS) was added under vigorous stirring. The solution was kept static at room temperature for $12 \mathrm{~h}$ for the hydrolysis.

The second part of the synthesis consisted of the selfassembly procedure through condensation of the silica by adding $2.7 \mathrm{~mL}$ of $0.25 \mathrm{~mol} \mathrm{~L}^{-1} \mathrm{NaF}$ and gently stirring in a thermostatic bath at $20^{\circ} \mathrm{C}$ for $30 \mathrm{~h}$. The precipitate was filtered and washed with water and ethanol. Next, the dispersion was dried in a chemical oven at $70{ }^{\circ} \mathrm{C}$ for $12 \mathrm{~h}$, ground and finally calcined at $500{ }^{\circ} \mathrm{C}$ for $5 \mathrm{~h}$, starting from room temperature and heating at a rate of $1{ }^{\circ} \mathrm{C} \mathrm{min}^{-1}$. The final white powder was stored at room temperature to be used in the synthesis of the Pd-based catalysts.

\section{Synthesis of $\mathrm{Pd} / \mathrm{SiO}_{2}$ and $\mathrm{Pd}$ NPs based on templated multifaceted mesoporous $\operatorname{lm} \overline{\mathbf{3}} \boldsymbol{m}$ silica}

$\mathrm{Pd} / \mathrm{SiO}_{2}$ NPs were synthesized by chemical reduction as described elsewhere ${ }^{24}$ mediated by poly(acrylic acid sodium salt) (PAA). The metallic content was adjusted to $40 \% \mathrm{Pd}$ on mesoporous silica. Briefly, adequate amounts of $\mathrm{PdCl}_{2}$ and mesoporous silica were mixed with a $3: 1$ solution of ethylene glycol (EG) : water in an ultrasonic bath for $20 \mathrm{~min}$. Next, PAA was added to obtain a monomer of PAA/Pd with an atom ratio of
3.0 and the mixture was sonicated for another $20 \mathrm{~min}$. The reaction bath was kept in an oil bath at $140{ }^{\circ} \mathrm{C}$ for $7.5 \mathrm{~h}$ and it was cooled to room temperature to form a dispersion of NPs. The dispersion was washed with deionized water and centrifuged three times to eliminate synthesis residues and finally dried in oven at $60{ }^{\circ} \mathrm{C}$ for $24 \mathrm{~h}$ to obtain a powder of $\mathrm{Pd} / \mathrm{SiO}_{2}$ NPs. Fig. 1 summarizes the synthesis of mesoporous silica and $\mathrm{Pd} / \mathrm{SiO}_{2}$.

Pd NPs were obtained by washing the $\mathrm{Pd} / \mathrm{SiO}_{2}$ NPs with hydrofluoric acid, which was sonicated for $30 \mathrm{~min}$ and centrifuged at $6000 \mathrm{rpm}$ three times. Such a procedure allows withdrawal of the mesoporous silica. Afterwards, the Pd dispersion was washed and centrifuged three times with deionized water and centrifuged at $6000 \mathrm{rpm}$. The Pd NPs dispersed in water were finally dried in an oven at $60{ }^{\circ} \mathrm{C}$ for $24 \mathrm{~h}$. The catalytic performance of the synthesized $\mathrm{Pd} / \mathrm{SiO}_{2}$ and $\mathrm{Pd}$ NPs was compared to commercial $\mathrm{Pd} / \mathrm{C}$.

\section{Electrode preparation and electrochemical experiments}

Dispersions of $\mathrm{Pd} / \mathrm{SiO}_{2}, \mathrm{Pd}$ and $\mathrm{Pd} / \mathrm{C}$ NPs were prepared by adding $1.0 \mathrm{mg}$ of $\mathrm{NP}$ powder to $1.0 \mathrm{~mL}$ water. To prepare the electrodes, an aliquot of the dispersion was deposited onto a 0.2 $\mathrm{cm}^{2}$ glassy carbon (GC) electrode, in order to produce a catalytic surface with $225.0 \mu \mathrm{g} \mathrm{cm}^{-2}$ loading, taking into account the mass of Pd on the GC electrode. To prepare Pd/C electrodes, we followed the same protocol, adding $30 \mu \mathrm{L}$ of diluted Nafion ${ }^{\circledR}(1$ $\mathrm{mL} 5 \%$ Nafion ${ }^{\circledR}$ in $20 \mathrm{~mL}$ 2-propanol) to the NPs immobilized on GC. This last step was taken because Pd/C NPs do not adhere as strongly to GC as do the $\mathrm{Pd} / \mathrm{SiO}_{2}$ and Pd NPs.

The electrochemical measurements were performed in a conventional three-electrode cell in an $\mathrm{N}_{2}$-saturated $0.1 \mathrm{~mol} \mathrm{~L}^{-1}$ $\mathrm{KOH}$ solution. We used a $\mu$ Autolab potentiostat/galvanostat with current integration. The modified GC was used as a working electrode. A high surface area Pt plate was used as the counter electrode and an $\mathrm{Ag} / \mathrm{AgCl}$ electrode was used as reference. All potentials were rescaled to a reversible hydrogen electrode (RHE) scale. The current density ( $j$ ) was calculated as the measured current divided by the electrochemically active surface area (ECSA), considering $420 \mu \mathrm{C} \mathrm{cm}^{-2}$ as the charge released by the desorption of a Pd oxide monolayer. ${ }^{25}$ All electrochemical experiments were carried out in triplicate at $25{ }^{\circ} \mathrm{C}$.

Prior to immobilizing the NPs on GC and starting the measurements, we carefully followed an electrochemical protocol to assure reproducibility among the experiments. Briefly, the previously polished and cleaned GC electrode was submitted to three cycles of cyclic voltammetry between -1.0 and $0.3 \mathrm{~V}(v s$. RHE) in $0.1 \mathrm{~mol} \mathrm{~L}^{-1} \mathrm{KOH}$ at $0.05 \mathrm{~V} \mathrm{~s}^{-1}$. Afterwards, the GC was washed with deionized water and dried with $\mathrm{N}_{2}$ and the NPs were finally deposited.

The electrochemical profiles of the catalysts were registered between 0.0 and $1.3 \mathrm{~V}$ in an attempt to investigate the hydrogen region and to monitor the surface orientation of the catalyst. ${ }^{26,27}$ On the other hand, the glycerol electrooxidation (in $0.2 \mathrm{~mol} \mathrm{~L}^{-1}$ $\left.\mathrm{GlOH}+0.1 \mathrm{~mol} \mathrm{~L}^{-1} \mathrm{KOH}\right)$ was performed between 0.57 and $1.3 \mathrm{~V}$ to avoid successively reaching potentials where hydrogen might absorb in the Pd crystalline net and destroy it accordingly 


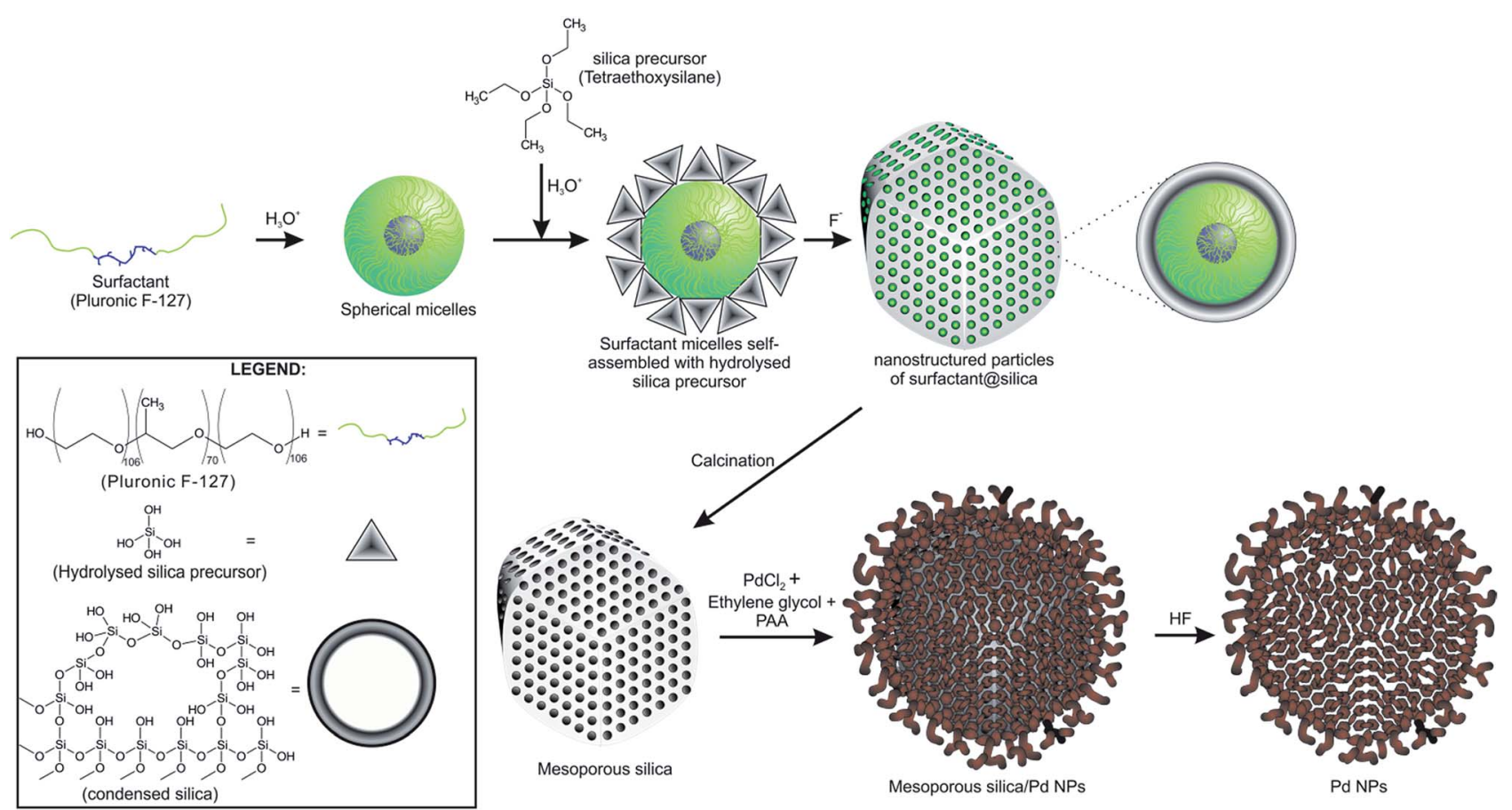

Fig. 1 Illustrative summary of the synthesis of mesoporous silica, $\mathrm{Pd} / \mathrm{SiO}_{2}$ and $\mathrm{Pd}$.

when desorbed. Chronoamperometry experiments were performed by stepping the potential at $0.77 \mathrm{~V}$ for $1800 \mathrm{~s}$ in the presence of glycerol. The stability of the nanomaterials in an electrochemical environment was investigated by following the current density peak of glycerol electrooxidation during 100 cycles of cyclic voltammetry between 0.47 and $1.3 \mathrm{~V}$ at $0.05 \mathrm{~V} \mathrm{~s}^{-1}$.

\section{Physical characterization of the materials}

The physical-chemical structure of the silica was investigated by small-angle X-ray scattering (SAXS), scanning electron microscopy (SEM), transmission electron microscopy (TEM) and $\mathrm{N}_{2}$-adsorption isotherms through the Brunauer-EmmettTeller (BET) method.

The study of pore symmetry was evaluated by SAXS experiments, at line D11A-SAXS of the Brazilian Synchrotron Light Laboratory (LNLS) in Campinas, Brazil. The samples were prepared by filling a metallic ring with the samples and sealed with Kapton ${ }^{\circledR}$ tape. The line used was equipped with an asymmetric slit, monochromator of silicon (111), monochromatic beam $(\lambda=1.488 \AA)$ and horizontal focus. Vertical and horizontal beam-stoppers were used to absorb direct and reflected X-rays, respectively. SAXS curves were analysed by calculating the values of scattering distances at planes $(h k l)$, indicated as $d_{h k l}$ for each peak, using the equation $d_{h k l}=2 \pi / q$, where $q$ is the scattering vector. ${ }^{28}$ The value of $d_{h k l}$ for the most intense peak corresponds to the mean interplanar distance of pores ( $d$-spacing). Pore symmetries and space groups were determined by calculating the $d$-spacing/ $d_{h k l}$ ratios and comparing these values with the literature. ${ }^{23,29}$ The unit cell parameter, $a_{0}$, was calculated by the expression $a_{0}=d_{110} \sqrt{2}$, as reported by Mesa et al. ${ }^{29}$
The shape and size of mesoporous silica were analysed by SEM at the Brazilian Nanotechnology Laboratory (LNNano) using a Jeol JSM-6330F microscope operating at $5 \mathrm{kV}$. The samples were metallized with gold, for $60 \mathrm{~s}$ with a current of $10 \mathrm{~mA}$ and vacuum of $2.0 \times 10^{-4} \mathrm{~atm}$.

The arrangement of internal mesopores in the silica samples was investigated by TEM in a Philips CM-30 microscope at the Centre d'Elaboration de Matériaux et d'Etudes Structurales (CEMES) in Toulouse, France. The samples were dispersed in ethanol, submitted to an ultrasonic bath for $5 \mathrm{~min}$ and deposited over a carbon-coated copper grid.

The BET method was employed to analyse the specific surface area $\left(S_{\mathrm{BET}}\right)$ and mean pore diameter $\left(D_{\mathrm{p}}\right)$ by experiments of adsorption and desorption of $\mathrm{N}_{2}$ at a constant temperature of $-196{ }^{\circ} \mathrm{C}(77 \mathrm{~K}) \cdot{ }^{30}$ The samples were previously degassed at $150{ }^{\circ} \mathrm{C}(423 \mathrm{~K})$ for $15 \mathrm{~h}$ and the experiments were carried using Micromeritics ASAP 2010 equipment. The wall thickness of pores, $t_{\mathrm{w}}$, was estimated by the equation $t_{\mathrm{w}}=\left(a_{0} \sqrt{3} / 2\right)-D_{\mathrm{p}}{ }^{29}$

$\mathrm{Pd} / \operatorname{lm} \overline{3} m\left(\mathrm{Pd} / \mathrm{SiO}_{2}\right), \mathrm{Pd}$ NPs and commercial $\mathrm{Pd} / \mathrm{C}$ were investigated through TEM images, dispersive X-ray spectrometry (EDS) and X-ray diffraction (XRD). The chemical composition of the catalysts was determined using a Leica-Zeiss LEO 440 scanning electron microscope at $20 \mathrm{kV}$ connected to a Link Analytical QX2000 energy-dispersive X-ray spectrometer and an SiLi $77 \mathrm{~K}$ cooled detector. The morphologies and sizes of the Pd NPs were analysed using a TEM JEOL model JEM2100 with an $\mathrm{LaB}_{6}$ filament operating at $200 \mathrm{kV}$. All samples were dispersed in 2-propanol and deposited onto a 400-mesh copper grid. AxioVision SE64 Rel. 4.8 software was used to study the images. The crystallographic structures of the Pd catalysts were studied by XRD using a Bruker D2 PHASER powder diffractometer 
equipped with a monochromatic Cu source with $\lambda=1.54 \AA$. The scans were collected with a step size of $0.05^{\circ}$ in the range $8-90^{\circ}$ and an interval of $5 \mathrm{~s}$ between steps.

\section{Results}

\section{Physical-chemical characterization of the multifaceted mesoporous $\operatorname{lm} \overline{\mathbf{3}} \boldsymbol{m}$ silica}

The structural properties of the multifaceted silica were deeply investigated before producing the Pd-based catalyst. Fig. 2 shows the SAXS curve of the synthesized silica. The SAXS profile suggests a highly patterned pore arrangement due to the presence of well-defined peaks, ascribed as X-ray scattering at the planes (110), (200), (211), (220), (310), (222), (321) and (330), characteristic of $\operatorname{lm} \overline{3} m$ spatial groups. ${ }^{31}$

The $d_{h k l}$ of the X-ray scattering listed in Table 1 are usually used to ascribe the symmetry of the porous arrangement and the spatial group, accordingly. Moreover, the ratio between $d_{110}$ and the $d$-spacing provided a sequence of constants $(1, \sqrt{2}, \sqrt{3}, \sqrt{4}, \ldots)$, which corroborates the characteristics of $\operatorname{lm} \overline{3} m$ spatial groups. ${ }^{31}$

Fig. 3 shows $\mathrm{N}_{2}$-adsorption isotherms of the silica. The isotherms were classified as type IV, according to IUPAC recommendations, ${ }^{32}$ characteristic of mesoporous materials. We can note a hysteresis loop between the adsorption and desorption curves,

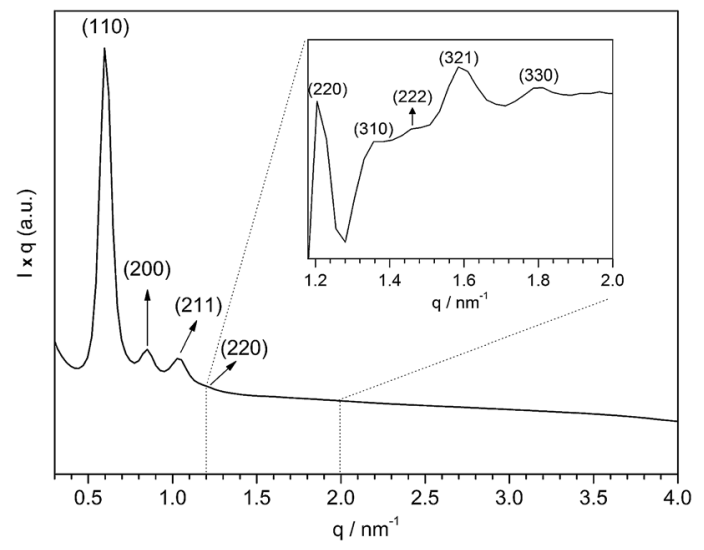

Fig. 2 SAXS curve of mesoporous multifaceted $\operatorname{lm} \overline{3} m$ silica.

Table $1 d_{h k l}$ values of mesoporous multifaceted $l m \overline{3} m$ silica obtained from SAXS

\begin{tabular}{lcl}
$(h k l)$ & $d_{h k l}(\mathrm{~nm})$ & Ratio $d_{110} / d_{h k l}$ \\
\hline$(110)^{a}$ & 10.6 & 1 \\
$(200)$ & 7.4 & $\sqrt{2}$ \\
$(211)$ & 6.1 & $\sqrt{3}$ \\
$(220)$ & 5.2 & $\sqrt{4}$ \\
$(310)$ & 4.6 & $\sqrt{5}$ \\
$(222)$ & 4.3 & $\sqrt{6}$ \\
$(321)$ & 4.0 & $\sqrt{7}$ \\
$(330)$ & 3.5 & $\sqrt{9}$ \\
${ }^{a} d_{110}=d$-spacing. & &
\end{tabular}

characteristic of pores in the form of a fountain pen, as occurs in the cage-like arrangement of pores of a body-centred cubic (bcc) structure. $^{33}$ This evidence is in line with the SAXS, corroborating the hypothesis of cubic $\operatorname{lm} \overline{3} m$ symmetry of pores. The silica presented a narrow diameter distribution estimated from the $\mathrm{N}_{2}$ desorption isotherm, as shown in Fig. 4. This result proves the success of the synthesis of silica with uniformly sized pores.

Confronting SAXS with BET data, other structure parameters of the silica were estimated (Table 2). Despite the specific surface area, the parameters were very close with those described elsewhere, ${ }^{29}$ indicating similar structural features to mesoporous $\operatorname{lm} \overline{3} m$ materials. The thickness of the silica walls $\left(t_{\mathrm{w}}\right)$ and the interplanar distance of pores calculated from $d_{110}$

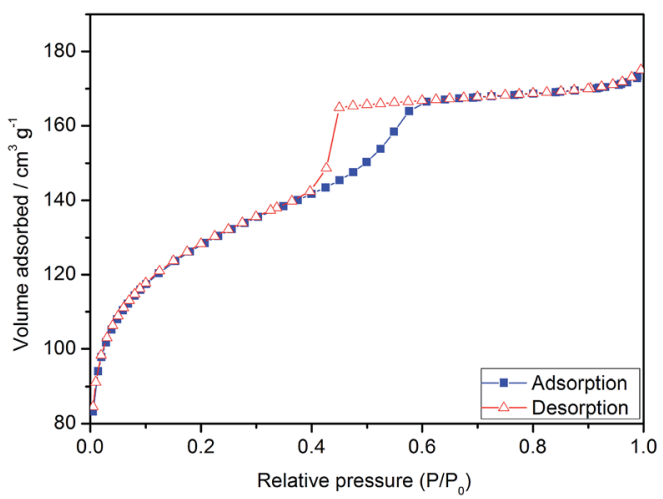

Fig. 3 Isotherms of $\mathrm{N}_{2}$ adsorption and desorption of multifaceted mesoporous $\operatorname{lm} \overline{3} m$ silica.

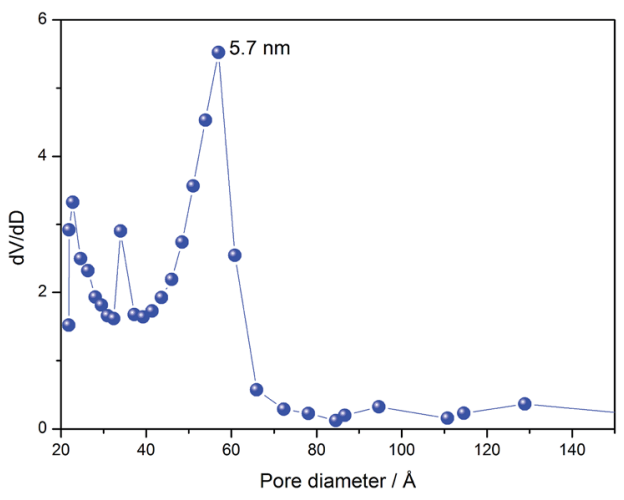

Fig. 4 Pore diameter distribution of multifaceted $l m \overline{3} m$ silica. Note: $\mathrm{d} V / \mathrm{d} D$ is the derivative of desorbed $\mathrm{N}_{2}$ volume over pore diameter.

Table 2 Structural parameters of mesoporous multifaceted $\operatorname{lm} \overline{3} m$ silica obtained from $\mathrm{N}_{2}$ adsorption/desorption isotherms ${ }^{a}$

\begin{tabular}{lllll}
\hline$S_{\mathrm{BET}}\left(\mathrm{m}^{2} \mathrm{~g}^{-1}\right)$ & $D_{\mathrm{p}}(\mathrm{nm})$ & $a_{0}(\mathrm{~nm})$ & $d_{110}(\mathrm{~nm})$ & $t_{\mathrm{w}}(\mathrm{nm})$ \\
\hline 446.0 & 5.7 & 15.0 & 10.6 & 7.3 \\
$908.0^{b}$ & $6.0^{b}$ & $15.9^{b}$ & $10.7^{b}$ & $7.8^{b}$
\end{tabular}

${ }^{a} S_{\mathrm{BET}}=$ specific surface area by the BET method; $D_{\mathrm{p}}=$ pore size by BET; $a_{0}=$ unit cell parameter calculated from $d$-spacing; $d_{110}=$ interplanar distance between pores; $t_{\mathrm{w}}=$ wall thickness of pores. ${ }^{b}$ Data from the literature..$^{29}$ 
were very similar to the literature, while the unit cell parameter $\left(a_{0}\right)$ and the mean pore diameter $\left(D_{\mathrm{p}}\right)$ were slightly smaller, which might be the reason for the difference between the $S_{\mathrm{BET}}$, as a result of the differences in the experimental procedures. Mesa et al. produced mesoporous silica in 5 days of aging at $95{ }^{\circ} \mathrm{C},{ }^{29}$ while our procedure only takes $30 \mathrm{~h}$ at $20^{\circ} \mathrm{C}$.
SEM images revealed that the silica particles had a uniform size distribution, shown in Fig. 5a. The synthesized silica presented an average mean diameter of $0.93 \pm 0.14 \mu \mathrm{m}$ and a narrow size distribution, as shown in Fig. S1. $\dagger$ In Fig. 5b, we can identify some bigger particles, indicating formation of a neck between two of them. This neck formation phenomenon is intimately
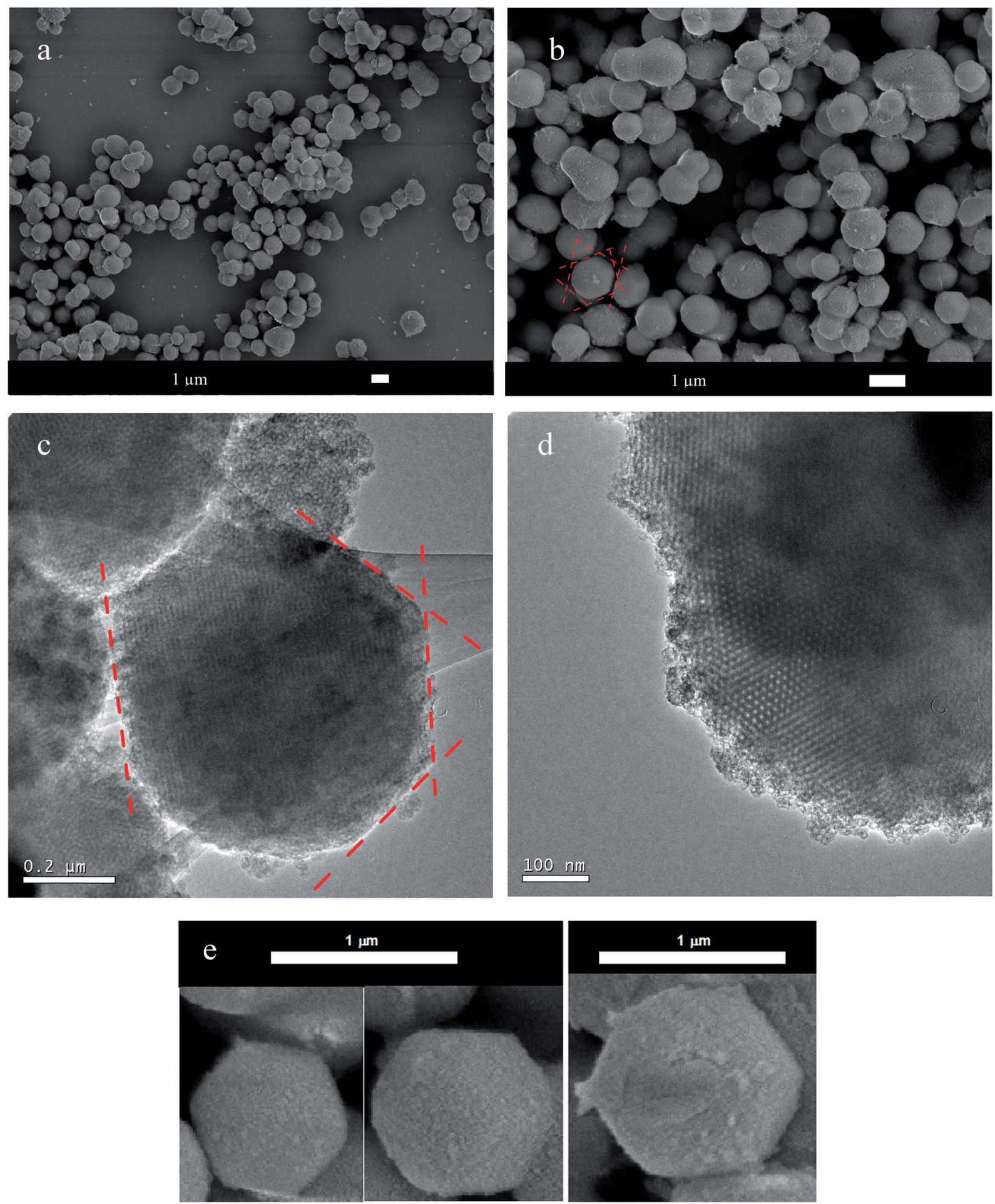

Fig. 5 Scanning electron micrographs ( $\mathrm{a}, \mathrm{b}$ and $\mathrm{e}$ ) and transmission electron micrographs (c and d) of the multifaceted mesoporous $I m \overline{3} m$ silica. The dashed red lines highlight the oriented facets. 
related with reactions at the solid-liquid interface, due to dissolution of small particles of early nucleation and reprecipitation over bigger particles, known as Ostwald ripening. ${ }^{34}$

SEM images (Fig. 5b and e) clearly showed the pattern of the material, which contained preferentially oriented facets in a polyhedron with smooth corners. Fig. 5e shows some selected well-ordered particles. The TEM images shown in Fig. $5 \mathrm{c}$ and d for multifaceted particles confirmed a highly ordered pore network, as suggested by the SAXS measurements.

This set of results proves the success of the synthesis of multifaceted well-ordered mesoporous $\ln \overline{3} m$ silica, which was used to produce patterned Pd NPs. The next section is devoted to the physical-chemical description of the Pd catalysts.

\section{Physical-chemical investigation of $\mathrm{Pd} / \mathrm{SiO}_{2}$ and $\mathrm{Pd}$ NPs based on an $\operatorname{lm} \overline{3} m$ silica template}

The chemical composition of $\mathrm{Pd} / \mathrm{SiO}_{2}$ and $\mathrm{Pd}$ NPs was investigated by EDS measurements, as shown in Fig. S2 and S3, $\uparrow$ respectively. The acid treatment of $\mathrm{Pd} / \mathrm{SiO}_{2}$ with $\mathrm{HF}$ solubilized the silica support, which was removed by washing and centrifuging with deionized water. Fig. $\mathrm{S} 2 \uparrow$ shows an intense Si signal and small signals for Pd, whereas the Si peak completely vanished in the EDS spectrum of Pd catalyst (Fig. S3†). This result proves the successful removal of the template from the metal catalyst. Moreover, we found by EDS that the metallic loading of $\mathrm{Pd} / \mathrm{SiO}_{2}$ was $36 \pm 2 \%$, which is close to the nominal composition (40\%).

Fig. 6 shows the XRD patterns of $\mathrm{Pd} / \mathrm{SiO}_{2}$ and $\mathrm{Pd}$ catalysts. Both catalysts showed peaks corresponding to $\operatorname{Pd}(111), \operatorname{Pd}(200)$, $\operatorname{Pd}(220), \operatorname{Pd}(311)$ and $\operatorname{Pd}(422)$ planes. The broad peak in the range of $2 \theta=15-35^{\circ}$ is ascribed as amorphous silica, ${ }^{21}$ which is absent after the removal of the silica (red line in Fig. 6). The most important feature is the high organization of the crystallites to form (111) planes, as depicted by the intense peak at $2 \theta=40^{\circ}$. The ratio between the intensities of (111) and (200) peaks $\left(I_{(111)}\right)$ $\left.I_{(200)}\right)$ of $\mathrm{Pd} / \mathrm{SiO}_{2}$ was larger than the value for a conventional powder sample (2.81 versus 2.38 (ref. 35)), suggesting that the surface arrangements of Pd were primarily composed of (111). The $I_{(111)} / I_{(200)}$ ratio decayed to 2.27 after the removal of the silica structure, suggesting a slight surface rearrangement, leading to an enrichment of (200) or a decrease of (111) defects.

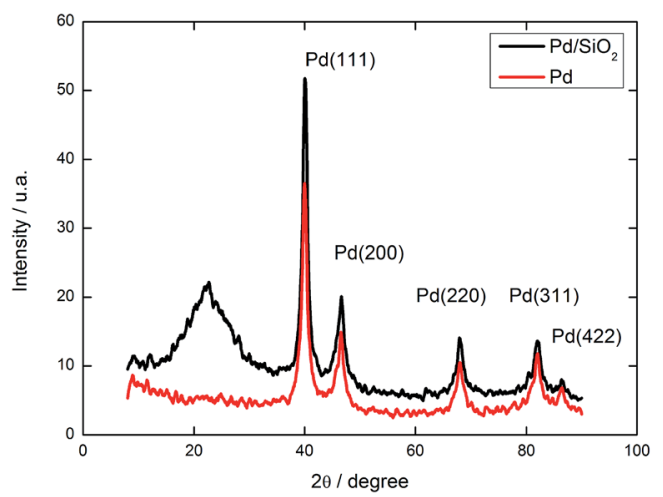

Fig. 6 XRD patterns of $\mathrm{Pd} / \mathrm{SiO}_{2} l m \overline{3} m$ and $\mathrm{Pd}$ NPs after removal of mesoporous silica.
Fig. 7 illustrates the microscopy investigation of the synthesized catalysts. The Pd NPs grew on the surface of the silica particles. Fig. 7a is a representative image of the whole catalyst, where we can find silica particles covered by Pd NPs and some silica completely free of metal. This feature is rationalized as a consequence of seedmediated growth, where a small cluster might work as a nucleation centre for clustering (NCC). ${ }^{\mathbf{1 4}}$ Accordingly, the Pd NPs build small clusters, which work as surface defects until complete coverage, while pure silica particles remain free of NPs. Once part of the silica is completely covered by $\mathrm{Pd}$ (with coverage degree $\theta_{\mathrm{Pd}}=1.0$ ), the $\theta_{\mathrm{Pd}}$ keeps increasing and the multiple layers of Pd progress as dendrites, as a consequence of the porous orientation of the multifaceted mesoporous silica. The growth pattern can be seen in Fig. $7 \mathrm{~b}$. Furthermore, we found Pd dendrites among $\mathrm{SiO}_{2}$ particles, in which growth took place led by the surface of multiple silica particles.

The use of a weak reducing agent (EG) during the chemical reduction method assisted by PAA allied to the preferentially oriented $\ln \overline{3} m$ silica allowed controlled growth of Pd NPs, yielding geometric organization such as dendritic shapes and a well-ordered atomic arrangement, evidenced in Fig. 7c. The NPs were grouped as clusters over the silica, thus we do not show any histogram of mean size distribution. However, we can clearly identify Pd NPs with sizes in the range of 5-15 nm. These Pd NPs showed fringes due to atomic level organization, resulting in the definition of atomic layers, as depicted in Fig. 7c. Such fringes are ascribed as partial orientation (111) defects, as suggested by the XRD patterns. Therefore, these results show that the Pd macro-orientation and the atomic level organization were induced through the shaped $\mathrm{SiO}_{2}$.

The spatial structures built through the Pd growth were kept after $\mathrm{SiO}_{2}$ removal, as shown in Fig. 7d. As a consequence, the Pd catalyst was constructed of several layers and pathways, producing microchannels in the form of a porous catalyst. We could find big particles with sizes close to the silica particles; however, the majority were smaller fragments as that showed in Fig. 7d. Fig. 7e shows some selected well-ordered Pd NPs. The use of an $\mathrm{SiO}_{2}$ template during the synthesis oriented the structure of Pd NPs to some extent but it is far from the level of preferential orientation reported by other groups. ${ }^{26,36,37}$ On the other hand, the presence of $\mathrm{SiO}_{2}$ in our one-step simple method organized the Pd NP structures leading to new and relevant catalytic properties, as presented in the next section.

The electroactivity of the synthesized nanomaterials was compared to commercial $\mathrm{Pd} / \mathrm{C}$, an image of which is shown in Fig. 7f. These NPs were well dispersed over amorphous carbon with an average size of $3 \pm 0.3 \mathrm{~nm}$ and an approximately spherical shape. It is worth noticing that we found several carbon supports free of Pd NPs in the TEM images. Thus, considering the heterogeneity of $\mathrm{Pd} / \mathrm{SiO}_{2}, \mathrm{Pd}$ and commercial NPs, we performed electrochemical experiments in triplicate and the results are shown as an average or representative.

\section{Electroactivity of $\mathrm{Pd} / \mathrm{SiO}_{2}$ and $\mathrm{Pd}$ NPs for glycerol electrooxidation}

Electrochemical measurements performed in $\mathrm{O}_{2}$-free solution using highly pure reactants and clean electrochemical cells are 


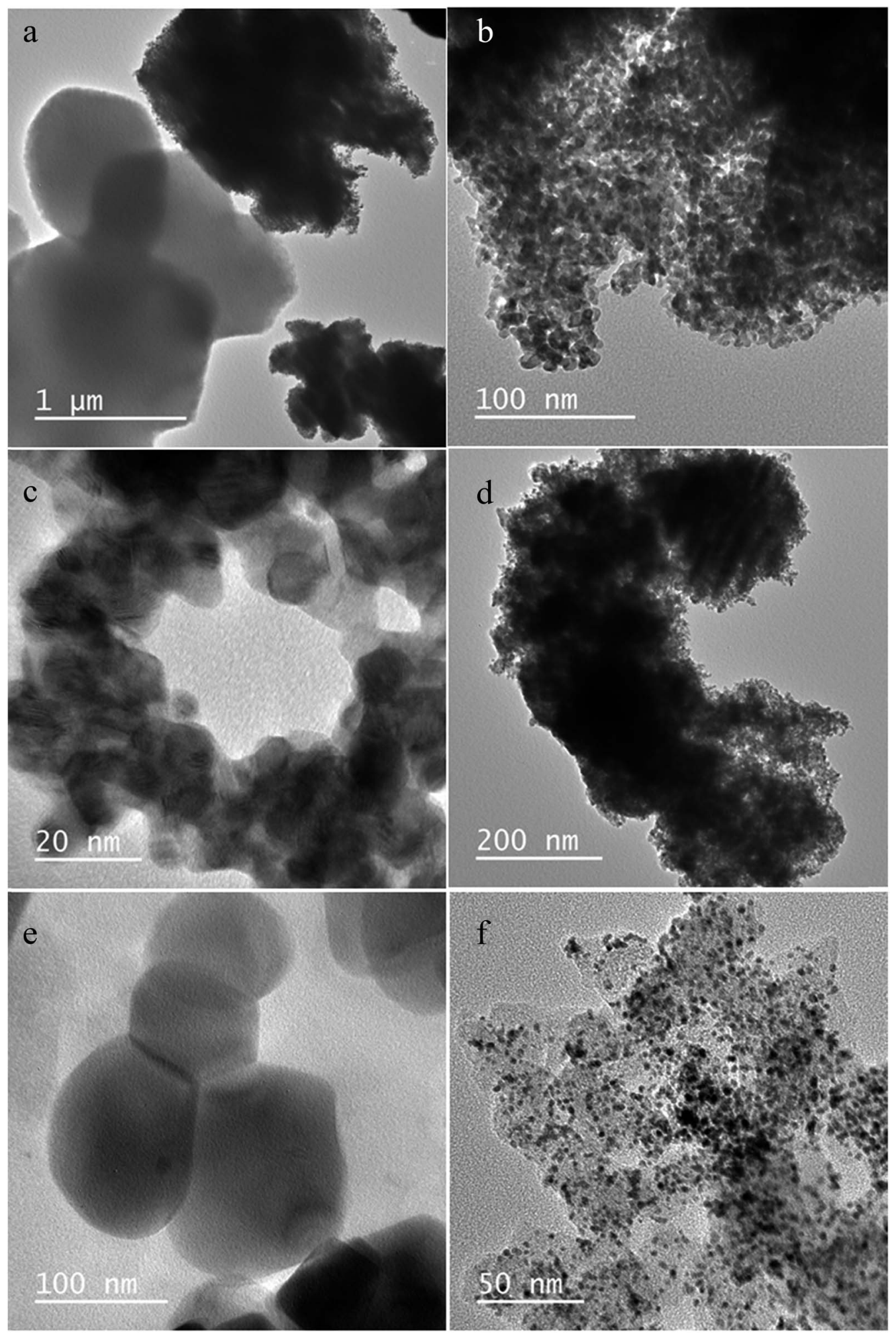

Fig. 7 Transmission electron micrographs of the $\mathrm{Pd} / \mathrm{SiO}_{2} \operatorname{lm} \overline{3} m(\mathrm{a}, \mathrm{b}$ and $\mathrm{c})$, the patterned Pd nanoparticles after removal of the multifaceted mesoporous silica ( $d$ and e) and of the commercial Pd/C nanoparticles ( $f$ ).

well known as powerful tools for in situ surface characterization. ${ }^{38}$ We recorded the electrochemical profile of the catalysts in $0.1 \mathrm{~mol} \mathrm{~L}^{-1} \mathrm{KOH}$ prior to their use in GEOR. Representative profiles are shown in Fig. 8. The formation of palladium oxides started at $\sim 0.67 \mathrm{~V}$ during the forward scan and were reduced during the backward scan, with a peak at $0.70 \mathrm{~V}$ for all catalysts (Fig. 8a and b). Hydrogen adsorbed on the Pd surface during the reverse scan and desorbed during the direct scan at a potential 


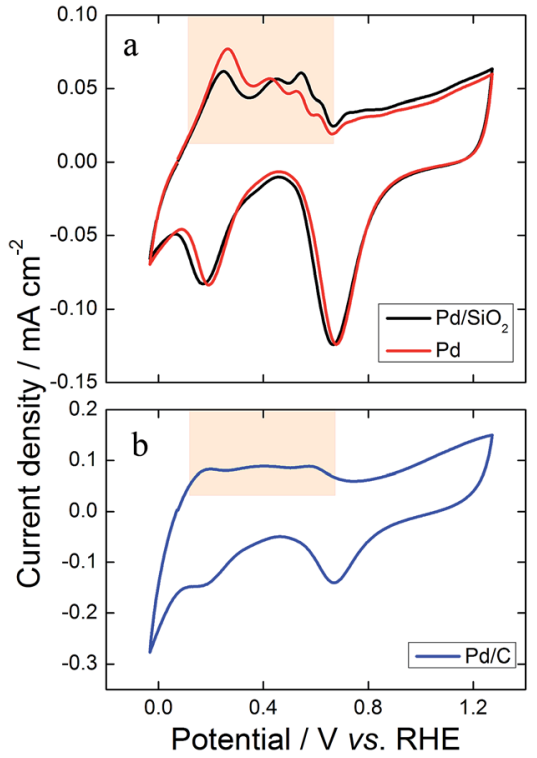

Fig. 8 Illustrative cyclic voltammograms recorded in the presence of $\mathrm{KOH} 0.1 \mathrm{~mol} \mathrm{~L}^{-1}$ at $0.05 \mathrm{~V} \mathrm{~s}^{-1}$ in the range -0.03 to $1.27 \mathrm{~V}$ (vs. RHE) for (a) $\mathrm{Pd} / \mathrm{SiO}_{2}, \mathrm{Pd}$ and (b) $\mathrm{Pd} / \mathrm{C}$ nanoparticles.

lower than $0.6 \mathrm{~V}$, developing evident cathodic and anodic peaks, respectively. The profiles were similar to those described by Bolzán. ${ }^{39}$ Moreover, the average ECSAs of the catalysts prepared with the same loading were $8.3,9.1$ and $2.2 \mathrm{~cm}^{2}$ for $\mathrm{Pd} / \mathrm{SiO}_{2}, \mathrm{Pd}$ and $\mathrm{Pd} / \mathrm{C}$, respectively. Hence, the use of mesoporous silica seems to facilitate the distribution of the Pd particles over the $\mathrm{SiO}_{2}$, which allied to the cleanness of the surface, enhance the ECSA. Additionally, the removal of $\mathrm{SiO}_{2}$ increases the ECSA, probably due to the clearance of active sites.

The hydrogen desorption region highlighted in Fig. 8 can be used to identify the preferential atomic orientation. Such regions were similar for $\mathrm{Pd} / \mathrm{SiO}_{2}$ and Pd (Fig. 8a), which were completely different from Pd/C (Fig. 8b). The spherical and very small size of $\mathrm{Pd} / \mathrm{C}$ maximizes the polycrystalline characteristics of the metallic catalyst. Otherwise, the ordered growth of Pd on $\mathrm{SiO}_{2}$ shown by the microscope images and the XRD patterns is confirmed by the electrochemical profiles through the welldefined hydrogen desorption peaks in Fig. 8a. Comparing the results in Fig. 8a with electrochemical features of Pd single crystals in an alkaline medium ${ }^{27}$ we could identify a relevant contribution of (111) planes on both synthesized materials, which is in line with the XRD patterns.

The electrocatalytic performance of $\mathrm{Pd} / \mathrm{SiO}_{2}$ and $\mathrm{Pd}$ catalysts for GEOR in an alkaline medium was investigated by cyclic voltammetry and compared with that of commercial Pd/C. The potential range $0.57-1.27 \mathrm{~V}$ was chosen to avoid hydrogen absorption during the surface reaction, which might result in the degradation of the catalyst when desorbing. An oxidation peak appeared in the positive potential scan direction, starting at $\sim 0.6 \mathrm{~V}$ for all three catalysts (Fig. 9a). The onset potential provides thermodynamic information regarding the influence of the catalyst in the initiation of the surface reaction. Thus, we can conclude that $\mathrm{SiO}_{2}$ used as a support or template to Pd NPs

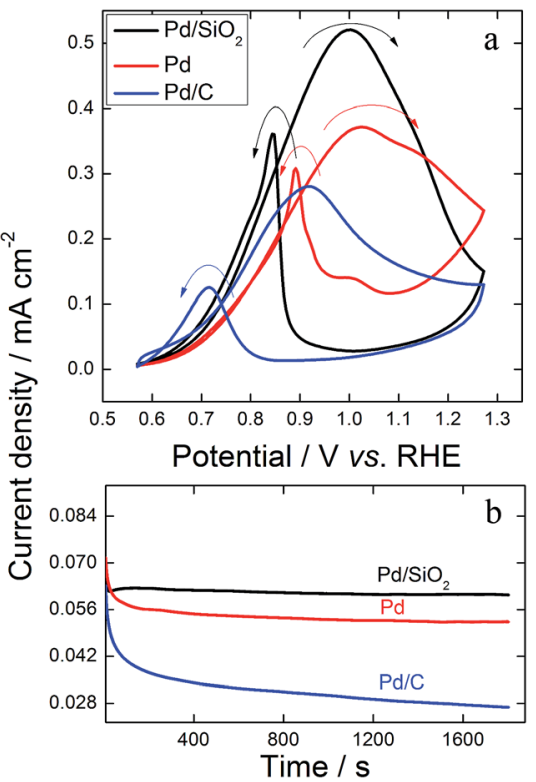

Fig. 9 (a) The fifth cyclic voltammograms and (b) chronoamperograms of the catalysts in the presence of $0.1 \mathrm{~mol} \mathrm{~L}^{-1} \mathrm{KOH}+0.2 \mathrm{~mol} \mathrm{~L}^{-1}$ $\mathrm{GlOH}$. Voltammetries performed in the range $0.57-1.27 \mathrm{~V}$ at $0.05 \mathrm{~V} \mathrm{~s}^{-1}$ and current-time curves recorded during $1800 \mathrm{~s}$ at $0.77 \mathrm{~V}$. The catalysts are indicated in the figure.

does not change the onset potential significantly. In general, multimetallic catalysts are required to shift the onset potential towards negative values. ${ }^{9,13}$ In this context, the start potentials of the studied materials were in line with previous reports regarding GEOR in an alkaline medium catalysed by Pd., ${ }^{9,10,13}$ Worth to note that $\mathrm{SiO}_{2}$ solely does not show any catalytic property.

The potential range and the definition of the anodic current during GEOR are highly dependent on the atomic surface arrangement of the catalyst. ${ }^{40,41}$ Although the synthesized materials were ordered, the diffusional process of glycerol and of its partially oxidized compounds through the catalysts resulted in a complex and sequential surface reaction with enlargement of the anodic peak accordingly. ${ }^{42}$ Nevertheless, $\mathrm{Pd} / \mathrm{SiO}_{2}$ and $\mathrm{Pd}$ showed an additional shoulder at 1.11 and $1.14 \mathrm{~V}$, respectively. These features can be better seen through the first derivative of the voltammogram $(d \mathrm{j} / d \mathrm{E})$ in Fig. S4. $\dagger$ The additional shoulders in the forward potential scan are a consequence of the patterned Pd structures of both $\mathrm{Pd} / \mathrm{SiO}_{2}$ and $\mathrm{Pd}$ catalysts. Here, we attributed the definition of peaks to the partially ordered surfaces, since GEOR on a single crystal would show single peaks instead of broad anodic transients, as found for Pt surfaces. ${ }^{40}$

Moreover, the backward scans of GEOR on the synthesized catalysts were sharper than those of Pd/C. Interestingly, the removal of the $\mathrm{SiO}_{2}$ resulted in a better definition of the shoulder during both forward and backward scans, the latter with an additional pre-peak. The reactivation ability for the reoxidation of intact glycerol or partially oxidized molecules inferred from the onset potential during the reverse scan followed the order $\mathrm{Pd}>\mathrm{Pd} / \mathrm{SiO}_{2}>\mathrm{Pd} / \mathrm{C}$. 
Regarding the catalytic effect in terms of output current, the current densities achieved using $\mathrm{Pd} / \mathrm{SiO}_{2}$ were twice those found for commercial Pd/C. GEOR was also improved using Pd after removal of the silica, which generated 1.5 times more current density at the oxidation peak compared with $\mathrm{Pd} / \mathrm{C}$.

Potentiostatic chronoamperometry experiments are usually performed to make catalysts experience a scenario closer to a real single fuel cell and, occasionally, these measurements are also used to evaluate the stability of NPs for the production of an electrochemical current over time. ${ }^{43}$ The output pseudostationary output current densities resulting from $1800 \mathrm{~s}$ of polarization at $0.77 \mathrm{~V}$ in the presence of glycerol were $0.06,0.05$ and $0.025 \mathrm{~mA} \mathrm{~cm}{ }^{-2}$ for $\mathrm{Pd} / \mathrm{SiO}_{2}, \mathrm{Pd}$ and $\mathrm{Pd} / \mathrm{C}$, respectively (Fig. 9b). The catalytic effect of $\mathrm{Pd} / \mathrm{SiO}_{2}$ enhanced GEOR by 2.4 times and twice by using Pd.

Therefore, the activity of the catalysts in terms of output current density and pseudo-stationary current density increased as follows: $\mathrm{Pd} / \mathrm{C}<\mathrm{Pd}<\mathrm{Pd} / \mathrm{SiO}_{2}$. These characteristics of GEOR on $\mathrm{Pd} / \mathrm{SiO}_{2}$ and on Pd catalysts have some influence of their ordered surfaces containing (111) defects, as shown in previous reports concerning enhancement in the activity of an organic molecule led by a controlled (111) surface of NPs. ${ }^{26,44}$ However, the $\mathrm{Pd} / \mathrm{SiO}_{2}$ architecture is the main responsible for the enhancement of GEOR. The mesoporous silica works as a cage, which confines intact glycerol and oxidized molecules so the reactants have an additional chance of colliding with active Pd sites when leaving the porous structure. After removing the $\mathrm{SiO}_{2}$, the current density decreased for $\mathrm{Pd}$ compared to $\mathrm{Pd} / \mathrm{SiO}_{2}$ catalyst due to the diminishment of reactant confinement. Hence, the mesoporous $\operatorname{lm} \overline{3} m$ silica synthesized for this study works with multiple functions, to build patterned Pd and to trap reactants. In this sense, $\mathrm{Pd} / \mathrm{SiO}_{2}$ displayed the highest catalysis for GEOR.

To understand, at least initially, how the porous clean structures of $\mathrm{Pd} / \mathrm{SiO}_{2}$ and $\mathrm{Pd}$ change the pathways of GEOR with improved kinetics (higher current density), we performed exhaustive cyclic voltammetry in the presence of alcohol and right after we transferred the catalyst to a clean electrochemical cell containing only electrolyte. Fig. 10 shows the electrochemical profiles in electrolyte for three successive cycles after exhausting GEOR. Remarkably, the first cycles for $\mathrm{Pd} / \mathrm{SiO}_{2}$ and Pd were precisely similar to stripping carbon monoxide (CO), where CO adsorbed to the surface is potentiodynamically removed to form $\mathrm{CO}_{2}$, producing a defined anodic peak. ${ }^{45}$ The first cycles in Fig. 10a and b showed profiles exactly as for CO stripping, with a hydrogen under potential deposition $\left(H_{\mathrm{UPD}}\right)$ region hidden due to the presence of adsorbed $\mathrm{CO}$, which was removed after its oxidation starting at $0.71 \mathrm{~V}$. The $H_{\mathrm{UPD}}$ region appeared in the second scans, proving that the CO monolayer was completely removed. Finally, the third scans matched exactly with the second ones, suggesting that there were no organic molecules on the catalytic surface. Otherwise, the anodic peak presented in the first cycle of GEOR on Pd/C persisted for the following cycles (Fig. 10c). Additionally, an anodic current appeared during the backward scan as a consequence of surface reactivation.

These results show that there was no glycerol or any kind of small-chain partially oxidized compound inside the porous

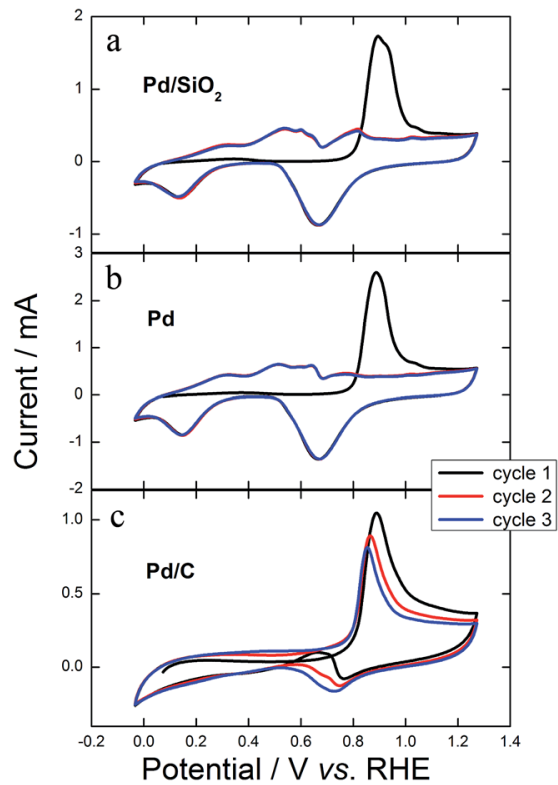

Fig. 10 Three successive cyclic voltammograms in $0.1 \mathrm{~mol} \mathrm{~L}^{-1} \mathrm{KOH}$ at $0.05 \mathrm{~V} \mathrm{~s}^{-1}$ for (a) $\mathrm{Pd} / \mathrm{SiO}_{2}$, (b) $\mathrm{Pd}$ and (c) $\mathrm{Pd} / \mathrm{C}$ after exhaustive cycles in the presence of $0.2 \mathrm{~mol} \mathrm{~L}^{-1} \mathrm{GlOH}+0.1 \mathrm{~mol} \mathrm{~L}^{-1} \mathrm{KOH}$.

architecture or on the surface of $\mathrm{Pd} / \mathrm{SiO}_{2}$ and $\mathrm{Pd}$. Only $\mathrm{CO}$ remained attached to $\mathrm{Pd}$ active sites and was rapidly removed, suggesting CO tolerance. Otherwise, glycerol, products, intermediates and certainly $\mathrm{CO}$ remained in the structure and surface of $\mathrm{Pd} / \mathrm{C}$.

We monitored the current density of peaks for 100 cyclic voltammograms in the presence of glycerol, as shown in Fig. 11. The values monotonously decreased for $\mathrm{Pd} / \mathrm{SiO}_{2}$, always maintaining the greatest currents. The current density increased during the first 50 cycles for $\mathrm{Pd} / \mathrm{C}$ due to a well-known surface cleaning process, ${ }^{45}$ therefore leading towards values comparable to Pd. However, Pd presented highly stable values after the $60^{\text {th }}$ cycle while the current kept decreasing for $\mathrm{Pd} / \mathrm{C}$ after a maximum at the $50^{\text {th }}$ cycle.

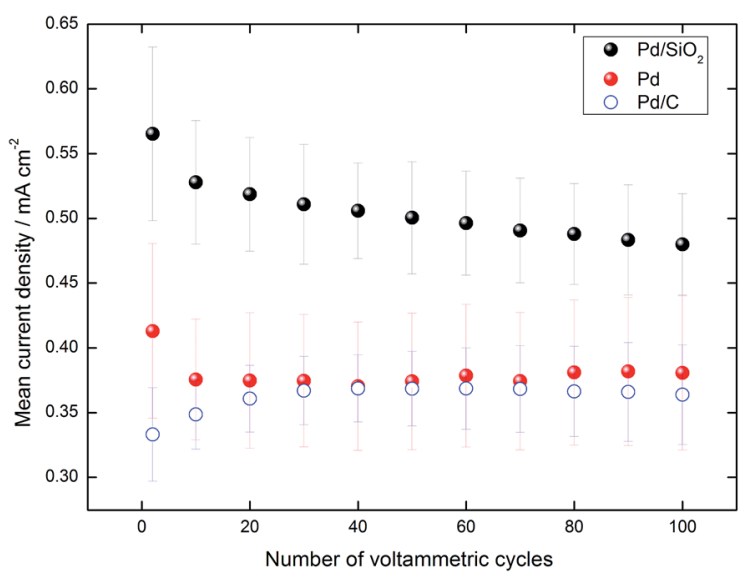

Fig. 11 Average current peaks of the anodic current of the positive scan during 100 potential cycles between 0.57 and $1.27 \mathrm{~V}$ at $0.05 \mathrm{~V} \mathrm{~s}^{-1}$ in $0.1 \mathrm{~mol} \mathrm{~L}^{-1} \mathrm{KOH}+0.2 \mathrm{~mol} \mathrm{~L}^{-1} \mathrm{GlOH}$. The standard deviations for three measurements are shown as light error bars. 
Fig. S5† evidences that both $\mathrm{Pd} / \mathrm{SiO}_{2}$ and $\mathrm{Pd}$ catalysts experience surface rearrangement after the 100 potential cycles. Although more investigation is needed, we suggest that the successive cyclic voltammetries in the presence of electrolyte and glycerol, reaching potentials where surface oxides are formed, i.e. $1.27 \mathrm{~V}$, must induce the polycrystalline structure.

Fig. 9b provides equivalent information regarding the stability in potentiostatic measurement. Comparing the current density at $300 \mathrm{~s}$ with that after $1800 \mathrm{~s}$ under applied potential, we found that $\mathrm{Pd} / \mathrm{SiO}_{2}$ and $\mathrm{Pd}$ lost $3 \%$ and $10 \%$ of their initial activity, respectively, while commercial Pd/C lost $45 \%$. These results evidence the outstanding stability provided by the new silica support used for GEOR. The patterned Pd also showed good stability, but the silica contributed more to the maintenance of the catalyst activity.

In summary, $\mathrm{Pd} / \mathrm{SiO}_{2}$ synthesized in one step from mesoporous silica improved glycerol electrooxidation in alkaline media by increasing the current density measured both potentiodynamically and potentiostatically. This new catalyst also enhanced the stability of the material. The increased activity is rationalized as the ability to trap reactants in the ordered structure and as an improved CO tolerance, since the electrooxidation of glycerol to $\mathrm{CO}_{2}$ via $\mathrm{CO}$ is one of the main pathways. The structure of $\mathrm{Pd} / \mathrm{SiO}_{2}$ builds an efficient structure capable of electrooxidizing intact and partially oxidized compounds by increasing the frequency of collision. Moreover, we showed that it is possible to remove $\mathrm{SiO}_{2}$ from the material and keep some of its catalytic benefits, which is important if the researcher chooses to use an oriented Pd catalyst deposited on other carbon or non-carbon supports.

\section{Conclusions}

We synthesized highly patterned mesoporous silica with pores in the form of a fountain pen and $\ln \overline{3} m$ symmetry in a cage-like arrangement of bcc structure. Such multifaceted mesoporous silica was used as a support to produce a patterned $\mathrm{Pd} / \mathrm{SiO}_{2}$ catalyst and as a template to synthesize a patterned Pd material.

$\mathrm{Pd} / \mathrm{SiO}_{2}$ NPs showed (111) orientation defects, whereas the surface was rearranged after removing $\mathrm{SiO}_{2}$ to produce $\mathrm{Pd}$ catalyst. The organization of the metallic content on silica is a consequence of seed-mediated growth led by the mesopores of the silica particles.

The silica pores in $\mathrm{Pd} / \mathrm{SiO}_{2}$ work as a trap that confines glycerol and its partially oxidized compounds, increasing the frequency of collision with Pd active sites while leaving the structure. Hence, the catalytic properties are enhanced, which increases the output current density compared to commercial $\mathrm{Pd} / \mathrm{C}$ material.

$\mathrm{Pd} / \mathrm{SiO}_{2}$ presents values of current density twice those found for $\mathrm{Pd} / \mathrm{C}$. The confinement effect leads to a more complete reaction, leaving no carbonyl compounds inside the structure except adsorbed CO. Moreover, the $\mathrm{CO}$ is rapidly removed from the $\mathrm{Pd} / \mathrm{SiO}_{2}$ surface, which is an additional role of the catalyst to improve GEOR.

$\mathrm{Pd} / \mathrm{SiO}_{2}$ showed superior stability to $\mathrm{Pd} / \mathrm{C}$. In potentiostatic experiments, the synthesized material lost $3 \%$ of its activity while $\mathrm{Pd} / \mathrm{C}$ lost $45 \%$. Moreover, the activity of $\mathrm{Pd} / \mathrm{SiO}_{2}$ was superior to the commercial catalyst for the whole degradation test protocol.

Pd catalysts also displayed improved activity and stability compared to $\mathrm{Pd} / \mathrm{C}$; however, $\mathrm{Pd} / \mathrm{SiO}_{2}$ reached the best performance. This result evidences that the mesoporous silica plays multiple roles, working as a stable support and as trap to reactants due to the cage-like structure.

Therefore, our results suggest that $\mathrm{Pd} / \mathrm{SiO}_{2}$ might be used as active and stable anodes for fuel cells and electrolysers fed by glycerol. Researchers or industrials might also use the patterned Pd catalyst deposited on different carbon or noncarbon supports for glycerol electrooxidation in alkaline media.

\section{Acknowledgements}

The authors acknowledge financial assistance from CNPq (Grant \# 454516/2014-2), FUNDECT (Grants \# 026/2015 and \# 099/2016), CAPES and FINEP.

\section{References}

1 C. A. Martins, M. J. Giz and G. A. Camara, Electrochim. Acta, 2011, 56, 4549-4553.

2 P. S. Fernández, M. E. Martins, C. A. Martins and G. A. Camara, Electrochem. Commun., 2012, 15, 14-17.

3 P. S. Fernández, C. A. Martins, M. E. Martins and G. A. Camara, Electrochim. Acta, 2013, 112, 686-691.

4 Y. Kwon and M. T. M. Koper, Anal. Chem., 2010, 82, 54205424.

5 O. O. Fashedemi, H. A. Miller, A. Marchionni, F. Vizza and K. I. Ozoemena, J. Mater. Chem. A, 2015, 3, 7145-7156.

6 Y. Kwon, T. J. P. Hersbach and M. T. M. Koper, Top. Catal., 2014, 57, 1272-1276.

7 A. C. Garcia, M. J. Kolb, C. van Nierop y Sanchez, J. Vos, Y. Y. Birdja, Y. Kwon, G. Tremiliosi-Filho and M. T. M. Koper, ACS Catal., 2016, 6, 4491-4500.

8 R. S. Ferreira Jr, M. Janete Giz and G. A. Camara, J. Electroanal. Chem., 2013, 697, 15-20.

9 A. Zalineeva, A. Serov, M. Padilla, U. Martinez, K. Artyushkova, S. Baranton, C. Coutanceau and P. B. Atanassov, J. Am. Chem. Soc., 2014, 136, 3937-3945.

10 A. Zalineeva, S. Baranton and C. Coutanceau, Electrochem. Commun., 2013, 34, 335-338.

11 N. Li, W.-Y. Xia, C.-W. Xu and S. Chen, J. Energy Inst., DOI: 10.1016/j.joei.2016.07.005.

12 L. Su, W. Jia, A. Schempf and Y. Lei, Electrochem. Commun., 2009, 11, 2199-2202.

13 X. Zhang and P. K. Shen, Int. J. Hydrogen Energy, 2013, 38, 2257-2262.

14 C. A. Martins, P. S. Fernández, F. de Lima, H. E. Troiani, M. E. Martins, A. Arenillas, G. Maia and G. A. Camara, Nano Energy, 2014, 9, 142-151.

15 A. K. Sahu, G. Selvarani, S. Pitchumani, P. Sridhar and A. K. Shukla, J. Electrochem. Soc., 2007, 154, B123-B132.

16 A. A. Melvin, V. S. Joshi, D. C. Poudyal, D. Khushalani and S. K. Haram, ACS Appl. Mater. Interfaces, 2015, 7, 6590-6595. 
17 S. N. Azizi, S. Ghasemi and E. Chiani, Electrochim. Acta, 2013, 88, 463-472.

18 J. Shim, J. Lee, Y. Ye, J. Hwang, S.-K. Kim, T.-H. Lim, U. Wiesner and J. Lee, ACS Nano, 2012, 6, 6870-6881.

19 J. Snyder, I. McCue, K. Livi and J. Erlebacher, J. Am. Chem. Soc., 2012, 134, 8633-8645.

20 N. Linares, A. M. Silvestre-Albero, E. Serrano, J. SilvestreAlbero and J. García-Martínez, Chem. Soc. Rev., 2014, 43, 7681-7717.

21 Q. Yao, Z.-H. Lu, Z. Zhang, X. Chen and Y. Lan, Sci. Rep., 2014, 4, 7597.

22 C. M. A. Parlett, D. W. Bruce, N. S. Hondow, A. F. Lee and K. Wilson, ACS Catal., 2011, 1, 636-640.

23 M. A. Ballem, J. M. Córdoba and M. Odén, Microporous Mesoporous Mater., 2010, 129, 106-111.

24 M. Chen and Y. Xing, Langmuir, 2005, 21, 9334-9338.

$25 \mathrm{H}$. A. Kozlowska, in Comprehensive Treatise of Electrochemistry, ed. E. B. Yeager, J. O. M. Bockris, B. E. Conway and S. Sarangapani, Plenum Press, New York, 1984, vol. 9, p. 2.

26 Q.-S. Chen, Z.-N. Xu, S.-Y. Peng, Y.-M. Chen, D.-M. Lv, Z.-Q. Wang, J. Sun and G.-C. Guo, J. Power Sources, 2015, 282, 471-478.

27 N. Hoshi, M. Nakamura, N. Maki, S. Yamaguchi and A. Kitajima, J. Electroanal. Chem., 2008, 624, 134-138.

28 M. Klotz, P.-A. Albouy, A. Ayral, C. Ménager, D. Grosso, A. Van der Lee, V. Cabuil, F. Babonneau and C. Guizard, Chem. Mater., 2000, 12, 1721-1728.

29 M. Mesa, L. Sierra, J. Patarin and J.-L. Guth, Solid State Sci., 2005, 7, 990-997.

30 S. Brunauer, L. S. Deming, W. E. Deming and E. Teller, J. Am. Chem. Soc., 1940, 62, 1723-1732.

31 D. Zhao, P. Yang, N. Melosh, J. Feng, B. F. Chmelka and G. D. Stucky, Adv. Mater., 1998, 10, 1380-1385.
32 J. Rouquerol, D. Avnir, C. W. Fairbridge, D. H. Everett, J. M. Haynes, N. Pernicone, J. D. F. Ramsay, K. S. W. Sing and K. K. Unger, Pure Appl. Chem., 2009, 66, 1739-1758.

33 P. I. Ravikovitch and A. V. Neimark, Langmuir, 2002, 18, 1550-1560.

34 C. J. Brinker and G. W. Scherer, Sol-Gel Science: The Physics and Chemistry of Sol-Gel Processing, Academic Press, 2013.

35 Y. Xiong, H. Cai, B. J. Wiley, J. Wang, M. J. Kim and Y. Xia, J. Am. Chem. Soc., 2007, 129, 3665-3675.

36 M. Jin, H. Zhang, Z. Xie and Y. Xia, Angew. Chem., Int. Ed., 2011, 50, 7850-7854.

37 W. Niu, L. Zhang and G. Xu, ACS Nano, 2010, 4, 1987-1996.

38 F. J. Vidal-Iglesias, R. M. Arán-Ais, J. Solla-Gullón, E. Herrero and J. M. Feliu, ACS Catal., 2012, 2, 901-910.

39 A. E. Bolzán, J. Electroanal. Chem., 1995, 380, 127-138.

40 P. S. Fernández, J. Fernandes Gomes, C. A. Angelucci, P. Tereshchuk, C. A. Martins, G. A. Camara, M. E. Martins, J. L. F. Da Silva and G. Tremiliosi-Filho, ACS Catal., 2015, 5, 4227-4236.

41 P. S. Fernández, C. A. Martins, C. A. Angelucci, J. F. Gomes, G. A. Camara, M. E. Martins and G. Tremiliosi-Filho, ChemElectroChem, 2015, 2, 263-268.

42 C. A. Martins, P. S. Fernández, H. E. Troiani, M. E. Martins and G. A. Camara, J. Electroanal. Chem., 2014, 717-718, 231-236.

43 L.-N. Zhou, X.-T. Zhang, W.-J. Shen, S.-G. Sun and Y.-J. Li, RSC Adv., 2015, 5, 46017-46025.

44 Y.-W. Lee, S.-B. Han, A.-R. Ko, H.-S. Kim and K.-W. Park, Catal. Commun., 2011, 15, 137-140.

45 C. A. Martins, P. S. Fernández, H. E. Troiani, M. E. Martins, A. Arenillas and G. A. Camara, Electrocatalysis, 2014, 5, 204212. 